\title{
La oposición antitrujillista, la Legión del Caribe y José Figueres de Costa Rica (1944-1949) ${ }^{1}$
}

\author{
María Dolores FERRERO \\ Universidad de Huelva \\ loferrero@yahoo.com \\ Matilde EIROA \\ Universidad Carlos III de Madrid \\ meiroa@hum.uc3m.es
}

Recepción: 27 de octubre de 2014 / Revisión: 19 de marzo de 2015

Aceptación: 28 de abril de 2015 / Publicación: Diciembre de 2016

\begin{abstract}
RESUMEN
En la década de 1940, los exiliados dominicanos, junto a otros centroamericanos, se unieron en la organización denominada Legión del Caribe con el objetivo de apoyarse mutuamente contra las dictaduras. Acordaron comenzar la lucha contra Trujillo y Somoza, pero la coyuntura aconsejó posponer los planes iniciales y se implicaron en la guerra civil o revolución de Costa Rica de 1948. Los dominicanos Horacio Ornes y Juan Rodríguez dirigieron la activa participación en el conflicto que terminaría con la toma del poder por José Figueres (presidente de facto de 1948 a 1949), que no hubiera sido posible sin la Legión del Caribe. Sin embargo, José Figueres no asumió posteriormente su compromiso con la Legión y las reclamaciones dominicanas nunca se atendieron.
\end{abstract}

Palabras clave: Legión del Caribe, dictaduras centroamericanas, José Figueres, Rafael L. Trujillo, Anastasio Somoza, Caribe, Siglo XX.

\section{The Anti-Trujillo Opposition, the Caribbean Legion and Costa Rica's Jose Figueres (1944-1949)}

\begin{abstract}
In the 1940's, exiled Dominicans and other Central-Americans joined together in an organization called the Caribbean Legion, with the objective of providing mutual support in the struggle against dictatorship. They began by agreeing to fight against Trujillo and Somoza, but circumstances favored the postponement of their initial plans, and their involvement in the Civil War or Revolution of Costa Rica of 1948 instead. Dominicans Horacio Ornes and Juan Rodriguez led the active participation in the conflict, which ended with the accession to power of Jose Figueres (de facto President between 1948 and 1949), whose presidency would not have been possible without the Caribbean Legion's involvement. Jose Figueres didn't comply with his commitments to the Legion, however, and the demands of the Dominicans were never attended.
\end{abstract}

\footnotetext{
1 Este artículo se enmarca en el proyecto de investigación de referencia HAR2012-37455-CO3-01 (MINECO).
} 
Keywords: Caribbean Legion, Central-American dictatorships, José Figueres, Rafael L. Trujillo, Anastasio Somoza, Caribbean, 20th Century.

Sumario: 1. Rafael L. Trujillo y la organización de la oposición al tirano. 2. Los dirigentes del exilio dominicano y las actuaciones contra el trujillismo. 3. La solidaridad con los opositores a las dictaduras: los dominicanos de la Legión del Caribe en la guerra civil de 1948 de Costa Rica. 4. El final de la Legión del Caribe y el incumplimiento de los pactos: deslealtad y traición de Figueres. 5. Referencias bibliográficas.

\section{RAFAEL L. TRUJILLO Y LA ORGANIZACIÓN DE LA OPOSICIÓN AL TIRANO}

La dictadura de Trujillo (1930-1961) se impuso en la República Dominicana después de ocho años de una intervención norteamericana que abandonó el país cuando ya estaban bien fijadas las raíces de lo que sería la tiranía trujillista.

La historiografía ha puesto de manifiesto que el régimen de Trujillo fue uno de los más duros de Centroamérica y el Caribe, desarrollado en el contexto de los Somoza de Nicaragua, Stroessner de Paraguay o Juan Vicente Gómez de Venezuela. Coincidió con todos, aunque no en las mismas fechas, pero fue uno de los primeros, avalado por el auge del fascismo, ya desde el inicio de la década de 1930. Después, se sirvió tanto de la coyuntura de la Segunda Guerra Mundial como de la complicidad norteamericana posterior en su posicionamiento anticomunista desde 1947. En palabras de R. Cassá:

La Guerra Fría facilitó un giro a favor de Trujillo en las altas esferas del imperialismo y el exilio perdió la oportunidad de la virtual neutralidad norteamericana que había existido hasta fines de 1946. Más que nunca, en adelante, Trujillo se tornaba en pieza útil de los entramados de la dominación sobre América Latina como punta de lanza contra los movimientos democráticos en la región caribeña ${ }^{2}$.

Desde entonces, Trujillo empezó a controlar las fuentes de riqueza de su país, monopolizando e interviniendo en toda empresa existente, desde los negocios más prósperos hasta los más turbios y creyó como pocos mandatarios en el poder de infundir temor y de "comprar" a sus opositores ${ }^{3}$. Sin embargo, hay sugerentes trabajos, como el de Andrés L. Mateo que han añadido a esas características tan particulares el notable papel que la eficaz propaganda tuvo en su encumbramiento, los halagos y homenajes, evidentemente inducidos, que se le dedicaban incansablemente, los escritores y biógrafos a sueldo en los que gastó verdaderas fortunas, en especial en los norteamericanos; y los panegíricos de toda clase, y en todo lugar, que fueron contribuyendo a una mitología muy del gusto de las clases más populares. Dicha propaganda, terminaría haciendo compatible una admiración, socialmente transversal, con el miedo

\footnotetext{
2 CASSÁ, 2010, p. 74.

3 Una práctica desconocida en otros dictadores fue la de ofrecer cargos a algunas personas de las que le habían combatido, para tenerlos sometidos y temerosos constantemente de cuando caerían en desgracia.
} 
y estado de alerta constante de la población, temerosa de caer en desgracia. Y ello porque "el verdadero telón de fondo de la ideología y el consenso era la violencia"4.

La bibliografía dedicada a Trujillo y a su gobierno es amplísima e inabarcable en un trabajo como el presente ${ }^{5}$. Sin embargo, aun las investigaciones referidas a las más diversas temáticas, son unánimes en señalar la multitud de dominicanos que tuvieron que exiliarse para salvar sus vidas. No existió una oposición interna permanente y visible porque no era posible en el seno de la más abyecta represión, tortura, venganzas tomadas en los familiares de los opositores, confiscaciones de patrimonios y muerte final casi segura de los alzados. Pero hubo brotes, pese a ello, desde los comienzos de la dictadura, a la vez que los exiliados se iban organizando desde los países de acogida.

En una sociedad cuyo sector predominante y sustento básico era un campesinado, siempre sin tierras, bajo una gran burguesía agraria latifundista, ligada al azúcar y a los negocios financieros relacionados con EE.UU., junto a una reducida clase de funcionarios o pequeños comerciantes -la llamada burguesía urbana-, el equilibrio no podía ser más que precario ${ }^{6}$. Trujillo había logrado controlar a los caudillos locales para afianzar su posición y había enriquecido aún más a la clase propietaria, a la vez que acrecentaba su fortuna personal y tejía una urdimbre social de enormes desigualdades y férreas fidelidades de sus protegidos ${ }^{7}$. No obstante, siempre hubo disidentes tanto entre hacendados como entre intelectuales y en parte de aquella burguesía urbana que terminó sintiéndose ultrajada por el férreo dominio del dictador. En consecuencia, siempre hubo intentos, desde dentro o desde fuera, de terminar con la dictadura.

La oposición interior se manifestó desde el comienzo de la década de 1930, a la par que se consolidaba el régimen y se asentaba el capitalismo monopolista en el país. Se dieron los primeros brotes de oposición burguesa de 1933 a 1935, aunque el fracaso del último complot de 1935 decidió a esa burguesía, en adelante, a colaborar con el trujillato. También hubo sediciones militares en los años 1933, 1934 y $1938^{8}$.

Más adelante, no solo temieron la represión carcelaria o policial, sino que el servicio de Inteligencia Militar (SIM) de Trujillo fue tan osado y eficaz que persiguió a enemigos políticos o "desafectos" dentro y fuera del país. Su perseverancia en el exterior nunca se sintió frenada por la lejanía de los lugares en que estuvieran los desterrados. La larga sombra de dicho organismo terminaba por alcanzarles y desaparecían sin dejar rastro ${ }^{9}$.

4 Mateo, 2004, p. 136.

5 Algunas obras imprescindibles, aunque publicadas hace años, para iniciar un estudio generalista sobre la dictadura de Trujillo serían: GalíndeZ, 1956; Ornes, 1958; Crassweller, 1966; WiARDA, 1970.

6 Veánse para el estudio económico del régimen: CASSÁ, 1984; 1992; 2000.

7 Para el estudio de esa sociedad que empezó a extinguirse a la muerte de Trujillo, en 1961, véase: FiaLLO, 2004.

8 Los intentos militares finalizaron con terribles desenlaces, como lo fue el del general José Paredes, caudillo de S. Pedro de Macorís, que había comentado que se iría "al monte a combatir a Trujillo", y fue asesinado tres días después sin haber comenzado a preparar su marcha. Y así, o con similar suerte, otros muchos que se alzaron en armas, como Alberto Larancuent, Cipriano Bencosme, Pedro A. Estrella, Evangelista Peralta, Desiderio Arias y Tancredo Savignon. Veáse excelente ampliación en: CoRDERO, 2009.

9 Consúltese sobre las diferenciaciones entre enemigos políticos, el trabajo de VEGA, 1986. Entre otros, fueron reseñados los secuestros y asesinatos en el exterior del líder obrero Mauricio Baéz, en La Habana, Manuel de Jesús Hernández Santana (Pipí Hernández), y Pablo Antonio Martínez; Andrés Requena y Jesús de 
No obstante, ya en esta época, la salida al exterior fue cada vez más el único recurso de los opositores políticos, siendo algunos de entre los más destacados, obligados a vivir en otros países, políticos y colaboradores personales del dictador. Fueron los casos del propio presidente Horacio Vázquez, antecesor derrocado de Trujillo, del vicepresidente José Dolores Alfonseca, de Andrés Francisco Requena, diplomático de su gobierno, o de Rafael Estrella Ureña, que había sido mentor político de Trujillo y presidente provisional a principios de 1930. Otros fueron simples adversarios políticos, como Federico Velázquez, Ángel Morales, Luis F. Mejía, Leovigildo Cuello, Miguel A. Pardo, Ramón de Lara, Horacio Ornes Coiscou y Juan Rodríguez García.

El propósito de este trabajo es dar a conocer, en especial, la contribución de dos exiliados, de entre todo el conjunto de Cuba, Puerto Rico, Guatemala, Panamá, Venezuela y Nueva York: Horacio Ornes Coiscou y el general Juan Rodríguez. Yerno y suegro, fueron ambos activos opositores al régimen de Trujillo, además de miembros fundadores de la tan significativa y conocida unión contra las tiranías centroamericanas, que se denominó Legión del Caribe ${ }^{10}$. Un mes después de la fundación del Pacto del Caribe, se les uniría José Figueres Ferrer, del Partido Socialdemócrata de Costa Rica.

La afortunada coyuntura de la entrega al Museo de la Memoria de Santo Domingo del formidable archivo privado de Horacio Ornes Coiscou -y el generoso ofrecimiento de su directora Luisa Peña- ha permitido la consulta exhaustiva del mismo, de donde ha sido posible sacar las semblanzas y actividad política de ambos opositores. Asimismo, una gran cantidad de aspectos desconocidos sobre sus relaciones, agradecimientos y decepciones con el resto de miembros de la Legión del Caribe y de los mandatarios de los países vecinos ${ }^{11}$. Esta rica documentación sustenta también la notable participación de la Legión en la guerra civil de Costa Rica de 1948, que llevaría al poder a la Junta presidida por José Figueres, y la posterior frustración dominicana ante la falta de reciprocidad de su gobierno.

El tema de la "traición" que vivieron los dominicanos por parte de Figueres, incluyendo el gran aporte económico de Juan Rodríguez, ha sido tratado ya, en parte, por Rosendo Argüello ${ }^{12}$-líder de los exiliados nicaragüenses- y por Guillermo Villegas Hoffmeister ${ }^{13}$. Sin embargo, los numerosos detalles en el desarrollo del proceso y la precisión de los datos cuantitativos que se acumularon en aquellos meses, se exponen en el presente trabajo gracias a la documentación primaria de un amplísimo dossier

Galíndez, en Nueva York, y hasta su antiguo secretario particular, el español José Almoina, en México. También atentó contra la vida de Tancredo Martínez García, representante del partido Vanguardia Revolucionaria. En Guatemala, se especuló con su participación en el asesinato de Castillo Armas y, en Venezuela, perpetró el fallido atentado del 24 de junio de 1960 a Rómulo Betancourt, cuyo descubrimiento marcaría el principio de su fin por el escándalo internacional y la presión irreversible ya sobre Estados Unidos.

10 La Legión del Caribe fue una organización de exiliados que buscaban el establecimiento de la democracia en la región centroamericana y caribeña. Había surgido en el contexto de la victoria europea contra el fascismo y nazismo tras la Segunda Guerra Mundial, dado que el triunfo de las democracias influyó intensamente en los pueblos latinoamericanos víctimas de dictaduras.

11 Archivo privado de Horacio Ornes Coiscou. Centro de Documentación del Museo de la Memoria (en adelante, AHOC/CDM). Santo Domingo, República Dominicana.

12 ARgüEllo, 1954.

13 Villegas Hoffmeister, 1998. 
del mencionado archivo, anejo a las numerosas cartas de reclamación de lo adeudado por Figueres. Aunque, por razones de espacio, se ha presentado solo el cálculo final de los datos, como se indica en el lugar correspondiente, es una información voluminosa y enormemente detallada la que recopiló Horacio Ornes, de la que hemos querido visibilizar lo que ha sido posible.

\section{LOS DIRIGENTES DEL EXILIO DOMINICANO Y LAS ACTUACIONES CONTRA EL TRUJILLISMO}

A mediados de la década de 1940, la coyuntura internacional de avance de los países aliados en la Segunda Guerra Mundial sirvió de impulso a una oleada de movimientos democráticos en la región: en Cuba ganó las elecciones de 1944 el Partido Revolucionario Cubano Auténtico -que llevó a la Presidencia a Ramón Grau San Martín-, en Guatemala cayó Jorge Ubico y subió al poder Juan José Arévalo y en Venezuela logró la presidencia Rómulo Betancourt, viejo enemigo de Trujillo.

Los exiliados dominicanos se adelantaron en cierta manera a la vorágine caribeña y celebraron un congreso de unidad en La Habana en febrero de 1944. En él, los más numerosos fueron los de posturas izquierdistas, agrupados en el Partido Revolucionario Dominicano (PRD), de ideología socialdemócrata, que se denominaba en ese momento Unión Dominicana Antinazi y cuyas figuras más conocidas fueron Juan Isidro Jiménez Grullón y Juan Bosch ${ }^{14}$. El resto, políticamente más a la derecha, estuvo encabezado por Ángel Morales, al que los anteriores acusaban de subordinación a EE.UU. Sin embargo, solo dos años después, la figura emblemática de la unidad de los exiliados fue Juan Rodríguez García desde que salió de la República Dominicana en 1946.

Junto a su yerno Horacio Ornes, exiliado en la misma fecha, Juan Rodríguez contactó y aglutinó a muchos exiliados de varios países centroamericanos, que prestaron una valiosa ayuda a la lucha contra las dictaduras, como lo fueron Jorge Rivas Montes, José María Tercero, Francisco Morazán, Francisco Sánchez, Marcos Ortega, Mario Sosa o López Godoy, todos ellos con residencia en Guatemala, apoyados durante años, entre otros, por los cubanos Manuel Castro y Eufemio Fernández ${ }^{15}$.

\footnotetext{
14 Juan Bosch sería uno de los fundadores del PRD en el exilio y uno de los organizadores de la expedición de Cayo Confites.

15 Fue un político cubano de la izquierda democrática que prestó una gran ayuda a los dominicanos desde la década de 1940. Horacio Ornes Coiscou, en su correspondencia personal con Figueres, Ruiz Cortines y Juan José Arévalo, lo define como un exiliado cubano, afecto a Prío Socarrás y asilado en México durante el mandato de Ruiz Cortines. Los citados políticos se manifiestan en muchas ocasiones preocupados por los varios secuestros que ha padecido Eufemio Fernández y porque afirman que si regresara a Cuba peligraría su vida. Finalmente, sería fusilado en la Cuba de Fidel el 20-4-1961, según Padilla Rus 2002, por haber sido uno de los jefes de la resistencia anticastrista; Cartas de Ornes a Figueres, a Ruiz Cortines y a J. J. Arévalo de 4 de junio a 21de agosto de 1955, y otra serie de Ornes al propio Eufemio Fernández durante marzo de 1957. AHOC/CDM, Caja 6. Telegramas de Horacio Ornes al Oficial Mayor de la Presidencia de la República de México, Luis García Larrañaga, a José Figueres y al presidente Ruíz Cortines, 9-5-1955. Correspondencia de Ornes de 1955 a 1959. AHOC/CDM, Caja 6.
} 
En una breve semblanza biográfica, habría que destacar que Horacio Ornes Coiscou fue bisnieto del general Pedro Antonio Pimentel, presidente de la República en 1865, y nieto de Emilio Prudhome, juez de la Corte Suprema y ministro de Instrucción Pública.

Dadas las dificultades de salir del país en la época de Trujillo, y siendo una de las formas el servicio exterior, Horacio Ornes -graduado en Derecho Diplomático y Consular- aceptó en 1944 el nombramiento de auxiliar del Consulado General de San Juan de Puerto Rico y, posteriormente, el de secretario de la Embajada y cónsul General de San José de Costa Rica, donde permaneció solo desde junio de 1945 a junio de 1946, pese a la holgada posición que le facilitaba dicho puesto ${ }^{16}$. En esa fecha, fue reclamado para desempeñar funciones en la Cancillería de Santo Domingo, pero él ya estaba vinculado a opositores del régimen; se declaró exiliado político, renunció a su cargo y se trasladó a vivir a Nueva York ${ }^{17}$.

Al año siguiente, en mayo de 1947, Ornes se presentó en La Habana para incorporarse a una expedición non nata que los exiliados dominicanos preparaban desde Cuba, la que después se denominaría Cayo Confites. Allí conoció al general Juan Rodríguez y fue asignado a la sección de Inteligencia y Comunicaciones de la expedición que no llegó a salir de Cuba. En junio de 1949, ambos se implicaron en la nueva expedición de Luperón, que Ornes dirigió, y fue uno de los cinco supervivientes de la misma ${ }^{18}$. Después, todos los integrantes fueron condenados a 30 años por la justicia dominicana, aunque la intervención de la OEA logró su amnistía a los ocho meses y Ornes salió de nuevo al exilio.

Asilado en Panamá, Cuba, México y EE.UU., residió en Puerto Rico de 1956 a 1961, trabajando en la revista Semana, del Departamento de Instrucción Pública. Allí contrajo matrimonio con una hija del general Juan Rodríguez, por lo que la relación entre ambos se estrechó merced a los vínculos de suegro y yerno.

Ornes fundó en Puerto Rico el partido Vanguardia Revolucionaria, que logró aunar a los exiliados dominicanos y llegó a tener secciones en Nueva York, Los Ángeles, Miami y Caracas, e, incluso, representaciones en otras ciudades europeas. Mantuvo

16 El subsecretario de Estado de Relaciones Exteriores de Trujillo, J. M. Bonetti Burgos, declaró que los honorarios de Ornes como Cónsul habían sido de 310,25 \$ por mes desde el 20 de octubre de 1945, tal como le comunicaron del The National City Bank of New York. Ornes renunció el 31-5-1946. Nombramientos y dimisiones. AHOC/CDM, Caja 7.

17 Ornes solicita que se tramite al Presidente una carta de renuncia a los cargos de secretario de la Legación de Costa Rica y de cónsul de la República Dominicana. Carta de Ornes a Trujillo, 6-6-1946, a través de su embajador César Tolentino. Correspondencia de Ornes de 1944 a 1950. AHOC/CDM, Caja 5.

18 Véanse para contrastar dos puntos de vista de la expedición de Luperón los libros de ORNES, 1956 y Arvelo, 1981. Ornes tuvo un gran interés en que Tulio H. Arvelo, persona de su absoluta confianza y respeto, le diera su opinión sobre el libro. Arvelo se lo elogió en la factura, le reconoció un esfuerzo de objetividad, pero le dice que, "si bien nadie podría tachar el libro de atrasado, tampoco se calificaría de progresista, porque su tesis se aparta de la línea correcta: habla del fracaso de la aventura, pero no condena la aventura misma Y eso era dejar la puerta abierta a que otros pudieran incurrir en el mismo error de seis años atrás". Arvelo opinaba que, incluso si hubieran llegado a derrotar a Trujillo, no hubiera sido el final de la explotación de las masas. Faltaban las circunstancias y condiciones para que una acción armada fuera una verdadera revolución. Sin embargo, cuando Tulio H. Arvelo publicó su propio libro, obvió ese tema y no aludió a nada similar. Correspondencia con Tulio Arvelo. Cartas de octubre de 1955 a enero de 1956 desde México a Nueva York. Correspondencia de Ornes de 1955 a 1959. AHOC/CDM, Caja 5. 
una intensa correspondencia entre 1955 y 1960 con José Figueres de Costa Rica, Ruíz Cortines y Luis García Larrañaga de México, Rómulo Betancourt de Venezuela, José Arévalo de Guatemala, el embajador en Puerto Rico, Luis Muñoz Marín, y la presidenta de la Asociación Interamericana por la democracia y la libertad, Frances Grant ${ }^{19}$.

Tras la muerte de Trujillo en mayo de 1961, fue candidato a la presidencia de la República por su partido, aunque renunció para apoyar la candidatura de Juan Bosch. Sin embargo, desacuerdos posteriores motivaron que Vanguardia Revolucionaria no participara en el gobierno de Bosch. En 1966 presidió la delegación dominicana en la ONU y en 1968 fue embajador de la misma y jefe de la Misión Permanente. En 1970 se retiró totalmente de las actividades políticas ${ }^{20}$.

En lo que respecta a la trayectoria personal y profesional del general Juan Rodríguez García -conocido por todos sus coetáneos como "Juancito"- habría que destacar que fue uno de los mayores latifundistas dominicanos, ganadero y productor de cacao. Radicalmente opuesto a los desmanes del trujillismo, que, tras el asesinato de varios de sus empleados, con la excusa de precisar un tratamiento médico, logró salir de la República Dominicana hacia Puerto Rico el 30 de enero de 1946. Dueño de una gran fortuna, estuvo durante meses sacando dinero del país clandestinamente para dedicarlo a la lucha contra Trujillo y con la idea de no regresar hasta que hubiera caído la dictadura.

Fue el organizador de las expediciones de Cayo Confites y Luperón, a lo que Trujillo respondió persiguiendo a varios miembros de su familia, que fueron asesinados, y a él lo despojó de todos los bienes que no sacó y que todavía quedaron en la República Dominicana. Para ello, impuso a todos los participantes de Cayo Confites el pago de la multa más alta de la historia judicial dominicana, 13 millones de dólares.

Además de su actividad contra Trujillo, como miembro fundador de la Legión del Caribe, financió con su patrimonio y recursos personales -los que había podido sacar del país- la guerra civil o revolución de 1948 de Costa Rica que elevaría al poder a José Figueres.

Según el testimonio de su yerno, Horacio Ornes, murió en el exilio, en Barquisimeto, Venezuela, seis meses antes de la muerte de Trujillo, el 19 de noviembre de 1960. Su decepción final por el incumplimiento costarricense del Pacto del Caribe y el no haber podido derribar la dictadura de Trujillo, se reflejaría en estas líneas de Ornes:

Arruinado y sin vislumbrar el final de la tenebrosa época que le tocó vivir, el general Rodríguez se suicidó. Posiblemente pensó en ese momento supremo como Bolívar, que había 'arado en el mar'21.

Diecinueve años después de su muerte, el 18 de julio de 1978, en el gobierno del mandatario Antonio Guzmán, sus restos fueron trasladados a su Moca natal y fue recordado por sus trabajadores como hombre justo y, por sus amigos como inflexible

19 Correspondencia de Ornes de 1955 a 1959. AHOC/CDM, Cajas 5 y 6.

20 Documentación de Horacio Ornes. AHOC/CDM, Caja 7.

21 Respuestas al cuestionario formulado por el periodista e historiador Guillermo Villegas Hoffmeister a Horacio Ornes. Santo Domingo, 10-6-1988. AHOC/CDM, Caja 10. 
ante lo deshonesto o incorrecto. En el discurso del obispo de San Pedro de Macorís, se dijo de él:

uno de los más ricos hacendados de la provincia de La Vega, aunque nacido en Moca. Allí llegó a tierras incultas y las convirtió en explotaciones de las más fértiles. Tuvo que soportar la envidia y robo de Trujillo y, como no se avino a sus deseos, la familia o todo el que estuviera relacionado con él, sufrieron persecución y descrédito de parte del régimen ${ }^{22}$.

El (PRD) le otorgó la condecoración más alta de la República, la Gran Cruz de Plata de Duarte, Sánchez y Mella, con motivo de ese homenaje póstumo. Se le elogió calurosamente por sus esfuerzos para unir en el exilio a los dominicanos de Guatemala, Cuba y Venezuela sobre todo y por haber gastado su patrimonio en luchas para la liberación de la República Dominicana. Sufrió la muerte de su hijo, José Horacio Rodríguez, en la gesta de 1959, de Constanza, Maimón y Estero Hondo, y murió sin ver logrado su sueño ${ }^{23}$.

El general Rodríguez había conseguido, sobre todo, conectar en el exilio a muchos opositores del interior, lo que fue siempre un objetivo frustrado porque realmente era una propuesta suicida para quienes vivían en la República Dominicana, y sólo en los últimos años de Trujillo se empezaría a organizar seriamente. Juan Bosch lo había intentado ya con el argumento de preparar un desembarco expedicionario en $1945 \mathrm{y}$ había buscado ayuda en los países vecinos logrando apoyo moral y material de Betancourt y Elie Lescot. Pero, según R. Cassá, esos preparativos carecían de virtualidad inmediata y, al parecer, buscaban más bien reactivar la oposición interna y unificar al exilio $^{24}$. Fue al año siguiente, en 1946, cuando el general Juan Rodríguez García se expatrió de República Dominicana y se puso al frente de los exiliados, constituyendo un gran estímulo para ellos.

La compra de armas era un tema complicado. El general Rodríguez las consiguió en Argentina, pagándolas en efectivo; las trasladó en aguas internacionales desde un barco argentino a otro de su propiedad y, pasando por Guatemala, desembarcaron finalmente en la Cuba de Grau San Martín con el mayor secreto. Para los tratos con Juan Domingo Perón, Juan Rodríguez contó con la valiosa mediación de Juan José Arévalo $^{25}$. Allí permanecieron las armas varias semanas hasta que, en junio de 1947, se pudo organizar el primer intento de invasión desde el exterior a la República Domi-

22 Discurso pronunciado por Monseñor Nicolás de Jesús López Rodríguez, obispo de San Francisco de Macorís e hijo de una sobrina carnal del general Rodríguez, “tío Juancito”. Santo Domingo, 28-7-1979. AHOC/CDM, Caja 10.

23 Discurso pronunciado por Rafael Álvarez Félix, presidente del Cabildo de Moca, con motivo de la inhumación de los restos del General Juan Rodríguez García, escrito por Víctor Lulo Guzmán. Santo Domingo, 28-7-1979. AHOC/CDM, Caja 10.

24 CAssí, 2010, p. 5.

25 La cantidad pagada por Juan Rodríguez fue de 78.000 dólares. La amistad de Arévalo con Perón provenía de los veinte años que aquel había pasado en Argentina, exiliado por Jorge Ubico. Desde entonces se había marcado el objetivo de luchar contra las dictaduras. Perón vendió las armas a bajo precio, creyendo que eran para el gobierno de Guatemala. Cuando se enteró de su finalidad, para contrarrestar, le vendió una cantidad mayor a Trujillo. ViLlegas HofFMeister, 1998, pp. 168-171. 
nicana, la conocida como Cayo Confites ${ }^{26}$. No obstante, la pretendida invasión quedó solo en el intento porque Grau San Martín no fue capaz de soportar las presiones de EE.UU. para que negara su territorio como punto de partida ${ }^{27}$. Junto a ello, el conocimiento de lo que se preparaba por parte de Trujillo y sus amenazas de bombardear La Habana, marcaron el final de la acción antes de su comienzo ${ }^{28}$. El 21 de septiembre de 1947, en medio de deserciones y noticias confusas, en la misma costa norte de Cuba, los expedicionarios fueron obligados a desembarcar y fueron detenidos. Las armas, confiscadas por Cuba, fueron finalmente entregadas al presidente Arévalo de Guatemala, que las reclamó y prometió su custodia ${ }^{29}$. La siguiente expedición contra Trujillo sería la de Luperón, en 1949. Pero antes de su preparación, la firma del Convenio entre exiliados, origen de la Legión del Caribe en 1947, antepondría al año siguiente los intereses de Costa Rica, donde nuevamente se implicarían Ornes y Rodríguez.

El perfil ideológico-político de ambos disidentes no fue el de revolucionarios al uso. Sin embargo, pertenecientes a la alta burguesía y profundamente anticomunistas, arriesgaron vida y fortuna para combatir la tiranía ${ }^{30}$. Su objetivo fue poner fin a los abusos de Trujillo e implantar un sistema democrático, y ese propósito solo tenía alguna posibilidad desde el exilio.

\section{LA SOLIDARIDAD CON LOS OPOSITORES A LAS DICTADURAS: LOS DOMINICANOS DE LA LEGIÓN DEL CARIBE EN LA GUERRA CIVIL DE 1948 DE COSTA RICA}

La Legión del Caribe, fundada en Guatemala siendo Juan José Arévalo presidente de la República, en noviembre de 1947, nació tras la redacción de un sencillo Convenio, firmado por dos dominicanos y un nicaragüense, a los que un mes después se uniría José Figueres ${ }^{31}$. Su propósito era comenzar actuando contra Anastasio Somoza García, de Nicaragua y Rafael Leónidas Trujillo Molina, de República Dominicana, aunque finalmente, Figueres lograría que Costa Rica se situara en primer lugar.

Horacio Ornes resumiría del siguiente modo su trayectoria en la última entrevista de su vida:

\footnotetext{
26 Llamada así por el nombre de un Cayo perteneciente al archipiélago cubano Camagüey, en el Atlántico. Véanse para ampliación del tema los trabajos de ARVELo, 1981 y VázQUEZ GARCíA, 2012.

27 VÁzQuez GARCÍA, 2012, p. 384.

28 Trujillo se enteró por el primer secretario de la Legación Británica en República Dominicana, Harry R. Hamleton, que visitó en la Cancillería dominicana al subjefe de la división de Protocolo de la Secretaría de Estado, Arturo Despradel, y por sus confidentes de Venezuela. Villegas Hoffmeister, 1998, p. 175.

29 Véase para una visión generalista del período: LiLón, 1999.

30 Horacio Ornes sería años después masón, como muchos de sus coetáneos, opositores democráticos a la dictadura. Fue inscrito con el número 83 de la Logia Masónica Luz Hispánica, "jurisdiccionada en la muy respetable Logia Valle de México", el 16 de marzo de 1957. Documentación de Horacio Ornes. AHOC/CDM, Caja 7.

31 Sus miembros fundadores fueron el general Juan Rodríguez, jefe de la oposición antitrujillista, de una parte y Emiliano Chamorro, por el Partido Conservador de Nicaragua y Rosendo Argüello, por el Partido Liberal Independiente (PLI) de Nicaragua, por la otra. Después se uniría a ellos José Figueres. Convenio del Pacto del Caribe, firmado en La Habana, el 14 de noviembre y el 16 de diciembre de 1947. Legión Caribe. AHOC/CDM, Caja10.
} 
El objetivo fundamental del Pacto del Caribe fue unificar a los desterrados de los distintos países de Centroamérica y el Caribe, con el propósito de desarrollar actividades comunes que permitieran la liquidación de las tiranías que oprimían a los pueblos de donde eran originarios los exilados. Fue una loable realización, pero, aunque parezca increíble, perdió vigencia con el primer triunfo en Costa Rica al incumplirlo Figueres. Fue un intento frustrado desde sus inicios para organizar militarmente a los exiliados de distintas nacionalidades. Por las mismas razones que no tuvo vigencia el Pacto, su ejército resultó non nato ${ }^{32}$.

De 1940 a 1948 se sucedieron en Costa Rica los gobiernos de Rafael Ángel Calderón Guardia y Teodoro Picado Michalski. El primero, del Partido Republicano Nacional, tomó importantes medidas -como la promulgación de un Código de Trabajo, la reforma que se llevó a cabo en 1941 de la Constitución de 1871, para introducir el Capítulo de las Garantías Sociales y la implantación del Seguro Social-, a favor de los trabajadores. Pero, aún así, no pudo evitar ser acusado de corrupción y vilipendiado por sus adversarios sobre todo por el apoyo del Partido Comunista que no fue más que una iniciativa pragmática ${ }^{33}$. El segundo, Teodoro Picado, ganó las elecciones de 1944 con el llamado Bloque de la Victoria, alianza entre el Partido Vanguardia Popular, el comunista, y el Partido Republicano Nacional. Su triunfo nuevamente fue cuestionado por la oposición, siendo dicha atribución objeto de posterior debate entre los autores: si realmente fue debido al fraude o a una perfecta estrategia del Partido Republicano Nacional ${ }^{34}$.

En las elecciones de febrero de 1948, Figueres apoyó a Otilio Ulate contra los denominados "caldero-comunistas", que fueron derrotados. Pero, acto seguido, aquéllos denunciaron un incendio parcial de papeletas y solicitaron la anulación del proceso. El logro de tal petición y la declaración de la nulidad de los comicios por parte del Congreso, tuvo como consecuencia el alzamiento en armas de José Figueres Ferrer y sus partidarios. Sería el inicio de la guerra civil o Revolución de 1948 de Costa Rica, que se prolongó desde el 12 de marzo hasta mayo del mismo año.

Las razones más profundas de Figueres para emprender dicho proceso han sido motivo de permanente debate. Algunas opiniones afirman que tomó las armas contra Calderón por la trayectoria electoral fraudulenta de aquél, que le había hecho virar hacia "la salida militar" 35 . Otros autores atribuyen el levantamiento a un supuesto anticomunismo figuerista, también objeto de encendida polémica entre los investigadores. Por ejemplo, M. Caballero valoró el hecho como uno de los escasos movimientos armados "no solo de un reformista no-marxista, sino de alguien abiertamente anti-

32 Respuestas al cuestionario formulado por el periodista e historiador Guillermo Villegas a Horacio Ornes. Santo Domingo, 10-6-1988. AHO, en CDM, Caja 10.

33 El Partido Vanguardia Popular de Manuel Mora era percibido en el país como costarricense y "criollo". No hubo suspicacias de ser corriente de transmisión del comunismo internacional, pese a la propaganda negativa de la oposición. El propio Manuel Mora era respetado y apreciado mayoritariamente.

34 Las acusaciones de corrupción de las elecciones de 1944 han sido formuladas por algunos autores, como Villegas Hoffmeister, 1998, y puestas en duda o desmentidas por otros, como Bell, 1981; Molina - LeHOUCQ, 1999.

35 Romero PÉrez, 1998, p. 41. 
comunista que siempre empleó, en la forma más ortodoxa, el lenguaje de la Guerra Fría" ${ }^{36}$.

M. Gamboa, sin embargo, considera que se produjo una utilización interesada del discurso anticomunista en el contexto internacional propio de la reciente política de bloques. El comunismo se calificó de ideología extraña y externa a la idiosincrasia costarricense -con un éxito indiscutible- y se identificó la lucha anticomunista con la defensa de la soberanía nacional ${ }^{37}$. En consecuencia, tras la Guerra Civil de 1948, el Partido Vanguardia Popular -el Partido Comunista de Costa Rica- sería declarado fuera de ley por el artículo 98 de la Constitución. De modo similar, Edelberto Torres asegura que Figueres no era un anticomunista dado que "las políticas que tomó entonces y después, profundizaron el ímpetu reformista que pusieran en marcha Calderón Guardia y los comunistas" ${ }^{\prime 3}$. En esa misma línea, R. Cerdas Cruz cita una carta a Edelberto Torres que Rosendo Argüello hijo -uno de los líderes nicaragüenses de la Legión del Caribe- hizo pública en 1958, en la que Figueres dice:

Yo no tengo ninguna objeción que oponer a la filosofía marxista, ni siquiera las de orden espiritual que a usted y a Rosendo les hace rechazarla, pero no cometo la torpeza de Manuel Mora de darle combate frontal al yanqui y al capitalismo ${ }^{39}$.

Todos los testimonios anteriores ponen de manifiesto que Figueres no era un acérrimo anticomunista, lo que abundaría en la teoría de la utilización interesada del "anticomunismo".

Poniendo el acento en otro aspecto muy diferente, otros autores, desde P. Bell a M. A. Solís, hacen hincapié en razones mucho más personales. El primero da importancia a su carácter de inmigrante catalán, solitario, con una educación férrea y autoritaria en su familia, que le llevaría a no soportar las actitudes dictatoriales. A ello se añadiría un deseo de destacar y un convencimiento de querer responder a una especie de "destino", que marcaría su vida política adulta: un objetivo en la vida de lucha contra los tiranos ${ }^{40}$.

Solís va más allá y llega a sostener que la base del ideario socialdemócrata en que decía sustentarse Figueres -el valor del socialismo, la libertad y la democraciaocultaba el deseo de compensar el agravio personal de su expulsión en 1942, que le impidió ser diputado electo y que él publicitó como un acto propio de una tiranía. De ser válido ese argumento, una de las causas más remotas de la decisión de Figueres de promover la revolución de 1948 se podría vislumbrar ya en el ascenso al poder de R. A. Calderón Guardia en 1940, dado que la acusación radiofónica que le hizo Figueres

36 CABAllero, 1987, p. 52.

37 GambOA, 2013, pp. 148-158.

38 Sobre todo, la nacionalización de la banca alteró la correlación de las fuerzas políticas a favor del campesinado y del mundo rural. TORRES, 2007, p. 72.

39 Manuel Mora Valverde era jefe del Partido Comunista de C. R. Vanguardia Popular. ArgüELlo, 1954, pp. 126-130; Cerdas Cruz, 1998, p. 33.

40 BeLl, 1981, pp. 123 y ss. 
le costó el exilio en 1942. Fue el único exiliado de Costa Rica, pese a existir otros críticos y disidentes y supuso para él una "extrema humillación" ${ }^{41}$.

Posiblemente influyeron todas, o algunas, de las razones mencionadas. Pero si las motivaciones de Figueres son complejas y debatidas, las causas más próximas de la guerra o el desencadenante final también han sido objeto de desacuerdo entre los investigadores: aunque la mayoría sitúa el peso en la anulación electoral de 1948, hay otros que atribuyen una gran importancia a la anterior "huelga de brazos caídos" de $1947^{42}$. La huelga había sido convocada a los dos días de una manifestación que se celebró en Cartago el 19 de julio de 1947 y que había sido reprimida con resultado de muertos. El paro fue total y transversal, acompañado de la reivindicación de garantías electorales para las próximas elecciones de 1948. Durante el conflicto, se intensificó el desprestigio de los procesos electorales de los años anteriores y se produjo un notable ascenso de los socialdemócratas que Figueres supo aprovechar para ultimar su decisión de alzarse en armas. Convenció a Arévalo de Guatemala -custodio de las armas de la Legión del Caribe- y a sus correligionarios de la urgencia de comenzar la lucha contra las dictaduras en Costa Rica ${ }^{43}$. Su argumento se basaba en el apoyo que Somoza estaba dispuesto a prestar a Calderón Guardia por su enemistad con Figueres. La convocatoria de elecciones para el 8 de febrero de 1948 era la oportunidad de frenar a Somoza:

Si ganamos aquí, tendremos un territorio y un arsenal a nuestra disposición. Si perdemos, lo tendrá a su disposición Somoza. Si Calderón se consolida, se fortalecerá definitivamente lo que es el frente sur de Somoza ${ }^{44}$.

Sin embargo, era muy forzado afirmar que luchar contra Calderón fuera hacerlo contra "una dictadura", por mucho que lo ayudara Somoza. De hecho, uno de los más notables partícipes en todos los movimientos antitrujillistas de la década de 1940, Tulio H. Arvelo, no se unió a los que apoyaban a Figueres, y criticaría posteriormente la actitud de los legionarios. Él no secundó la iniciativa porque el gobierno de Calderón Guardia era el seguido por las fuerzas más progresistas del país, mientras que Otilio Ulate, su oponente, era un oligarca que representaba la reacción costarricense. Fue evidente que los exiliados de la Legión optaron por el pragmatismo para conseguir después ayuda para su causa ${ }^{45}$. Siguiendo al pie de la letra los Convenios de la Le-

41 No se conocen las razones de fondo de la decisión de Calderón. En cuanto al efecto provocado en Figueres, Solís interpreta que muchos rasgos de Calderón le recordaban al padre rígido e inflexible y la resolución de expulsarle del país fue vivida por él como insoportable. Solís, 2006, pp. 359-363; 2007-2008, pp. $261-295$.

42 Calderón, 2002. Véanse también, en cuanto al tratamiento de la huelga: Rojas, 1986; BeLL, 1976; Rodríguez, 1980; ACuÑa, 1992; Aguilar Bulgarelli, 2004; LehouCQ, 1997; Molina - LehouCQ, 1999.

43 Bell considera que a Arévalo fue utilizado porque él pretendía crear una Unión Centroamericana que defendiera la democracia y combatiera las dictaduras, pero ése no fue finalmente el objetivo de José Figueres. BELL, 1981, p.140.

44 Carta de José Figueres a Juan Rodríguez García, 22-12-1947. Legión Caribe. AHOC/CDM, Caja10.

45 Arvelo, 1981, pp. 108-109. 
gión, el compromiso colocaba en primer lugar la lucha contra Somoza y Trujillo, pero las condiciones más favorables de Costa Rica modificaron los planes ${ }^{46}$.

La participación legionaria en la guerra civil se formalizó con el documento que el general Miguel Ángel Ramírez Alcántara envió a los miembros de la Junta de Gobierno de Costa Rica. En él concretaba que la Legión del Caribe facilitaría las armas y reclutaría hasta seiscientos hombres para formar dos batallones al servicio del gobierno de Costa Rica. Siempre bajo el mando del Comandante en Jefe, que no era otro que Figueres, al que había nombrado el propio general Rodríguez por considerarlo "capaz y con dotes de mando" 47 .

Las armas, que fueron esenciales para el triunfo de Figueres, fueron las que se habían destinado a la expedición de Cayo Confites, que habían quedado depositadas en Guatemala ${ }^{48}$. Propiedad, en su mayoría, del general Rodríguez y tan esenciales en la victoria figuerista como la cooperación de los oficiales de la Legión del Caribe. Ellos entrenaron y dirigieron al pequeño ejército de intelectuales, estudiantes, campesinos y obreros costarricenses, que conformaban el grupo oposicionista de Figueres, sin experiencia alguna en resistencia ni combate. Un ejemplo de su influencia queda patente en la mención que hace el general Rodríguez de la planificación de la toma de Puerto Limón, diseñada por él y comandada por Horacio Ornes. Dice literalmente lo siguiente:

me permito recomendarle que trate por todos los medios posibles de obtener la conquista de un puerto en la Costa Atlántica, pues si es necesario, por esa vía podría enviarle un equipo mucho mayor, así como valientes y expertos combatientes que podrían ser de utilidad para el éxito de su misión. En consecuencia, es necesario que las fuerzas revolucionarias bajo su mando se apoderen cuanto antes de Puerto Limón o de otro que ofrezca seguridades para operaciones de mayor escala ${ }^{49}$.

Asimismo, le anuncia el envío de sus mejores oficiales para que le ayuden en la contienda:

Para garantizar el envío y para cooperar con usted, me permito enviarle un grupo de oficiales de mi mayor confianza, a quienes les ruego atender con las mayores consideraciones y utilizarlos en los lugares que más necesarios sean (...) son jóvenes que luchan con sinceridad por los principios democráticos y anhelan para sus respectivas Patrias gobiernos decentes que garanticen las libertades ciudadanas y la justicia social que tanto necesitan nuestros oprimidos pueblos ${ }^{50}$.

\footnotetext{
46 Aguilar Bulgarelli, 2004, pp. 180-182; Convenio del Pacto del Caribe, firmado en La Habana, el 14 de noviembre y el 16 de diciembre de 1947. Legión Caribe. AHOC/CDM, Caja10.

47 Líneas Generales grosso modo del entendimiento de la Legión para prestar su apoyo y colaboración a las fuerzas del gobierno de la Honorable Junta de Costa Rica. Firmado por M.A. Ramírez. Legión Caribe. AHOC/CDM, Caja 10.

48 BeLl, 1981, p. 140.

49 Carta del General Rodríguez a José Figueres del 12-3-1948. Legión Caribe. AHOC/CDM, Caja 10, p. 3.

50 A este respecto menciona al Mayor Jorge Rivas Montes, al Capitán Francisco Morazán, al Teniente Mario Sosa y al teniente coronel M.A. Ramírez, como representante militar suyo y al Capitán Horacio Ornes, como su representante personal con el cargo de Delegado Político del Presidente del Comité Supremo Revolucionario. Ibídem, p. 2.
} 
Pero toda esa disponibilidad y generosos ofrecimientos eran hechos en la completa seguridad de que se iba a cumplir el pacto de caballeros acordado y firmado cuando todos estaban en el exilio y Figueres era un simple opositor. Dando por supuesto que Figueres correspondería después para seguir derribando el resto de las tiranías del Caribe y Centroamérica:

Desde que me informé de la situación de su país en La Habana, decidí prestarle toda mi ayuda; puede estar seguro de que no escatimaré ningún esfuerzo, contando, desde luego, con la firme participación de ustedes para solucionar, más adelante, la situación de todos los países del área del Caribe que se encuentran sometidos a regímenes despóticos ${ }^{51}$.

El general Rodríguez, en ese momento, estaba encantado con Figueres y le comunicaba también su nombramiento como jefe de las fuerzas que operan en Costa Rica "por sus merecimientos" 52 . Figueres le agradeció el envío de oficiales y elogió su comportamiento en reiteradas ocasiones en los meses posteriores. Y, por supuesto, no olvidaba responder a su alusión de reciprocidad, asegurando siempre que el fuego no cesaría hasta derrocar a Trujillo. Figueres se mostraba confiado en que se llegaría a fundar la Segunda República de Costa Rica -a fin de cambiar la Constitución- y que, entonces, junto a la Confederación del Caribe, sería "el asilo de los hombres libres"53.

Tras la toma de Puerto Limón y de otras acciones relevantes, como la batalla de El Tejar, una de las más duras, y después del asedio de Tarbaca y S. Ignacio de Acosta, la guerra había llegado a un empate a mediados de abril de 1948. Figueres tenía la ciudad de Cartago y había tomado Limón, pero las otras cinco provincias, incluida la capital, estaban en manos del gobierno de Teodoro Picado. Entre tanto, el Presidente había solicitado la ayuda de Anastasio Somoza García y el 17 de abril llegaron tropas de la Guardia Nacional de Nicaragua a la población costarricense de Villa Quesada. Sin embargo, ante la reacción desfavorable de EE.UU., el 19 de abril, dos días después de su llegada, las tropas nicaragüenses tuvieron que retirarse.

Tras las tomas de Cartago y Puerto Limón, el Estado Mayor ya informó a Picado de la situación precaria y la falta de armas. Pero a Picado le decidió a considerar su renuncia, sobre todo, el deseo de evitar un derramamiento de sangre mayor después de "la carnicería de El Tejar" ${ }^{4}$. El presidente reunió al cuerpo diplomático y éste nombró una comisión que llegó a un pacto con Figueres en la Embajada de México de San José para poner fin a la guerra. Al día siguiente, el Presidente Picado presentaba su renuncia e informaba a R.A. Calderón Guardia y a Manuel Mora -para que lo comunicaran a sus respectivos partidos- que no podía continuar la guerra: además de carecer de armas y dinero, buscaba llegar a la paz, aseguró tener datos de la existencia de "fuerzas incontrastables" y de un posible "vejamen" al que el país sería sometido

51 Carta del General Juan Rodríguez a José Figueres, 12-3-1948. p. 3. Revolución Costa Rica 1948. Legión Caribe. AHOC/CDM, Caja 10, p. 4.

52 Ibídem, p. 2.

53 Cartas de José Figueres al General Juan Rodríguez. 13-5-1948 y 2-4-1948. Revolución Costa Rica 1948. Legión Caribe. AHOC/CDM, Caja 10.

54 BELL, 1981, p. 198. 
si el conflicto continuaba unos días más, así como de que "iban a perder esa partida". Por todo ello, instaba a los suyos a deponer armas, evitar una tragedia y lograr garantías para vidas y haciendas de los perdedores ${ }^{55}$. Había decidido abandonar Costa Rica con destino a Nicaragua y llamar al ejercicio temporal de la presidencia al Tercer Designado, aceptado por el resto, Santos León Herrera ${ }^{56}$.

El 8 de mayo de 1948 se instalaba una Junta Fundadora de la Segunda Repúbli$c a$-un gobierno provisional con Figueres Ferrer como presidente de facto- que se prolongaría hasta el 8 de noviembre de 1949. Sin embargo, todavía en diciembre de 1948, Calderón -argumentando después que no había tenido noticia del pacto firmado en la Embajada de México- desde Nicaragua y con ayuda de Somoza, invadió de nuevo Costa Rica. La intervención de EE.UU. obligó a ambos países a poner fin a las hostilidades. Y Nicaragua firmó un convenio de amistad con Costa Rica, del que fue garante la recién creada OEA ${ }^{57}$. La guerra de Costa Rica había terminado y se acercaba la disolución de la Legión del Caribe.

\section{EL FINAL DE LA LEGIÓN DEL CARIBE Y EL INCUMPLIMIENTO DE LOS PACTOS: DESLEALTAD Y TRAICIÓN DE FIGUERES}

\subsection{Las reclamaciones de los legionarios de la Legión del Caribe}

Las armas dominicanas de Cayo Confites llevaron a Figueres a la victoria en la guerra de Costa Rica. Sin embargo, en toda la documentación o publicaciones provenientes de los protagonistas dominicanos miembros de la Legión y de las expediciones contra Trujillo, se constata que Figueres no correspondió a la ayuda dominicana. En palabras de Tulio Arvelo, participante en las dos expediciones de la década de 1940 contra Trujillo -Cayo Confites y Luperón- después de que Figueres alcanzara sus objetivos:

No hizo buena su promesa y, según supe más tarde, solamente contribuyó con un dinero que había prometido así como con la devolución de una parte de las armas de Cayo Confites que le había "prestado" don Juan Rodríguez de la cantidad que éste había conseguido que le devolvieran en $\mathrm{Cuba}^{58}$.

José Figueres había triunfado, pero no le hubiera sido posible sin la Legión del Caribe, cuyo éxito indiscutible fue la victoria en la guerra civil o revolución de Costa

55 Véase para mayor ampliación: Carta del presidente de la República de Costa Rica, Teodoro Picado Michalski, a R.A. Calderón Guardia y a Manuel Mora anunciándoles su dimisión. 18-4-1948. Revolución Costa Rica 1948. Legión Caribe. AHOC/CDM, Caja 10; Aguilar Bulgarelli, 2004, pp. 207-235; Bell, 1981, pp. 200-201.

56 Se llamó así al nombramiento de una tercera persona para el gobierno provisional -de solo dieciocho días- que estableció un puente entre Picado y la Junta Fundadora de la Segunda República.

57 La OEA comenzó afirmando apoyar a todos los gobiernos por igual para evitar conflictos en Centroamérica y El Caribe, pero terminó apuntalando el status quo e, indirectamente, legitimando dictaduras. Véase a este respecto, AMERINGER, 1996. Señalando mayor protagonismo a EE.UU., véase: Cerdas CruZ, 1998.

58 ARVElo, 1981, p. 108. 
Rica de 1948. Lo que no esperaban sus correligionarios vecinos era que, una vez en el poder, Figueres abandonaría el Pacto y pondría el punto final a la Legión en 1950. Horacio Ornes también se lamentaría de lo ocurrido tras el triunfo costarricense, muchos años después, del siguiente modo:

El compromiso de Figueres con el general Rodríguez, el que establecía el propio pacto de la Alianza de diciembre de 1948 -que el general Rodríguez recordó en carta del 26 de julio de 1948- no se cumplió por lo que, paradójicamente, la victoria de Figueres significó en breve la derrota de las aspiraciones de los revolucionarios centroamericanos y dominicanos ${ }^{59}$.

Pero hasta confirmar la decepción de dichos incumplimientos, el proceso fue largo y las demandas del general Rodríguez a Costa Rica reiterativas y constantes. En cada una de ellas, el general se remitía a lo que habían convenido dos años atrás, en los compromisos que habían comenzado con el primer Convenio, germen de la creación de la Legión del Caribe, firmado el 14 de noviembre de 1947, que decía literalmente:

El señor General Juan Rodríguez García, Jefe de la oposición activa al régimen de Trujillo en la República de Santo Domingo, de una parte; el señor General Emiliano Chamorro, como presidente de la Junta Directiva Nacional y Legal del Partido Conservador de Nicaragua y el señor Doctor Rosendo Argüello, como presidente de la Junta Directiva del Partido Liberal Independiente de Nicaragua, de otra parte,

Considerando la necesidad de unir todos los esfuerzos y recursos para el derrocamiento de las dictaduras mantenidas por lo Generales Rafael Leónidas Trujillo M. y Anastasio Somoza en sus respectivos países, han convenido en lo siguiente:

I.-Habiendo comenzado ya en Nicaragua la lucha armada contra la tiranía somocista, y siendo urgente el reforzamiento de la guerra en Nicaragua, el General Juan Rodríguez se obliga a proporcionar inmediatamente a los nicaragüenses la ayuda en elementos de guerra, que consta en hoja separada. También se obliga a traspasar a los nicaragüenses, a título de préstamo, en el más breve plazo posible, los otros elementos adquiridos en EE.UU. de América. Conviene, además, dicho General, en hacer todas las activas gestiones pertinentes ante el Gobierno de Cuba, para recuperar el armamento y demás armamentos, ahora depositados en manos de dicho Gobierno, los cuales pondrá también en manos de los nicaragüenses, para ser usados contra Somoza y su régimen.

II. Los nicaragüenses aquí representados por los señores General Chamorro y Doctor Argüello, por su parte, se obligan frente al General Rodríguez y los dominicanos, tan pronto sea derrocado el régimen de Somoza, a lo siguiente:

a) Romper toda clase de relaciones con Trujillo y su régimen y usar su influencia ante los otros gobiernos de América para que condenen y combatan la tiranía de Trujillo. b) Poner a disposición del General Rodríguez una base aérea y marítima donde pueda organizarse la expedición aéreo-marítima contra Trujillo y su régimen. c) Devolver al General Rodríguez una cantidad de elementos de guerra igual a la recibida y prestar de sus propios arsenales una cantidad, por lo menos igual, a la prestada por el General Rodríguez, que deberá devolverse tan pronto como sea destruido el régimen

59 Respuestas al cuestionario formulado por el periodista e historiador Guillermo Villegas a Horacio Ornes. Santo Domingo, 10-6-1988. AHOC/CDM, Caja 10. 
de Trujillo. Comprometiéndose a considerar como propia la causa del pueblo dominicano bajo la Jefatura del señor General Rodríguez.

El presente Convenio ha sido celebrado en la ciudad de La Habana, República de Cuba, y se pondrá en efecto inmediatamente después de firmado, a los catorce días del mes de noviembre del año mil novecientos cuarenta y siete. Entre líneas de-Vale: Juan Rodríguez; Emiliano Chamorro; Rosendo Argüello.

Nota: Me adhiero al presente Convenio en lo que respecta a Costa Rica. Guatemala, 16 de diciembre de 1947. José Figueres ${ }^{60}$.

En el texto se muestra cómo Figueres se adhirió un mes después al acuerdo. Ni siquiera había sido miembro fundador. También es obvio que el principal propósito de la Legión del Caribe era comenzar con el derrocamiento de los regímenes de Trujillo y Somoza -que no lograron en modo alguno, ni siquiera debilitar-, aunque más tarde se pospuso y el éxito rotundo lo alcanzó el propósito de Figueres: su ascenso al poder en Costa Rica.

\subsection{El incumplimiento de Figueres con el Convenio de la Legión del Caribe}

El malestar del general Juan Rodríguez comenzó muy pronto tras del triunfo de Figueres en Costa Rica. Poco después de la toma del poder por la Junta tuvo dudas sobre el comportamiento de Figueres y sospechas de que fuera a olvidar los términos de los acuerdos, una vez que había logrado sus propósitos y tenía innumerables tareas en su propio país. Una vez instaurada la Junta de Gobierno en Costa Rica, el general había escrito a Figueres, como presidente de la misma, solicitándole una aportación de dinero para pagar una compra de aviones a EE.UU., que él estaba efectuando con vistas a proseguir las acciones contra Trujillo. Pero Figueres había enviado un cable indicando que solo se vendiera según instrucciones de Argüello, lo que molestó mucho al general, que retiró la petición y se indispuso con Figueres $^{61}$. Respecto a esta intromisión del citado Argüello, Ornes comentó mucho tiempo después que nunca había entendido su relación con Figueres. En su opinión, Figueres lo utilizaba haciéndole creer que iba a ayudarle en la lucha contra Somoza -imponiéndolo a los nicaragüenses en el exilio, a pesar de que no confiaban en

60 Convenio de Constitución. 14-11-1947. Legión del Caribe. AHOC/CDM, Caja 10. Más tarde, en diversas ampliaciones del Convenio fue firmado también por Gustavo Manzanares, Pedro José Zepeda y Rosendo Argüello, de Nicaragua. El presidente de Guatemala, Juan José Arévalo, siempre ayudó en los propósitos de los legionarios, igual que Rómulo Betancourt, de Venezuela. Ideológicamente, la aspiración común era el logro de un sistema democrático y una gran parte de los fundadores fueron masones. No en vano, Trujillo mantuvo un enfrentamiento constante con Betancourt, Arévalo, Ramón Grau San Martín, de Cuba, y Elie Lescot, de Haití, que ayudaban o simpatizaban con sus adversarios. Entretanto, haciendo honor a su autodenominación de "Primer Anticomunista de América", y como muestra de devoción a EE.UU., cuidaba mucho sus relaciones con las dictaduras de Juan Domingo Perón, de Argentina, Anastasio Somoza, de Nicaragua, e, incluso, con Francisco Franco, de España.

61 Lo que el general solicitaba a Figueres para la compra de aviones era 40.000\$, la suma de 20.000\$, como devolución de lo gastado por él en la revolución de Costa Rica, y otros 20.000\$ en virtud de los acuerdos de igualar -en préstamo- la cantidad gastada. Por ello era impropia la intromisión de Argüello en algo que sólo competía al general Rodríguez. Carta del General Juan Rodríguez a Figueres, 1-7-1948. Revolución Costa Rica 1948. Legión Caribe. AHOC/CDM, Caja 10. 
él- cuando en realidad maniobraba para que no se diera la unión de los exiliados contra Somoza ${ }^{62}$.

Si lo anterior había supuesto una contrariedad para el general, muy poco después las cosas empeoraron y Rodríguez dirigiría una larga serie de cartas recordándole a Figueres sus compromisos. La más detallada es de tres meses después de su triunfo el 26 de julio del 1948, donde le reclamaba que cumpliera lo pactado en el Convenio de 1947. Rodríguez se lamentaba de que Figueres solo hubiera cumplido parcialmente la condición de la ruptura de relaciones con Trujillo, pero no los acuerdos sobre materiales de guerra y equipos. Sintetizando, el general pedía a Figueres que le dotara de tantas armas como él le había facilitado para la guerra de Costa Rica y le prestara una cantidad por lo menos igual a aquella, tanto en armas como en dinero. Asimismo, que financiara los aviones pagados por él o le abonara su importe, más otro tanto en préstamo para dar cumplimiento al Convenio. Por último, le rogaba que realizara esa devolución lo antes que pudiera para tener todo preparado el 30 de agosto de 1948, fecha límite acordada para la devolución ${ }^{63}$.

Dado que Figueres manifestó que no podía tener preparada la reparación de la deuda para la fecha especificada en el Convenio, el general M.A. Ramírez -Comandante de la Legión del Caribe- y José Horacio Rodríguez -hijo del general Juan Rodríguez, que actuaba en representación suya- llegaron a un acuerdo de pagos parciales con los delegados de la Junta de Gobierno de Costa Rica ${ }^{64}$. Los representantes del general Rodríguez aceptaron en septiembre de 1948, en atención a los argumentos de pobreza de Costa Rica, el abono de 125.000 \$ en aquel momento. Por otra parte, el gobierno de la Junta de Costa Rica había gastado de abril a septiembre de 1948 otros 64.783 \$, siendo el total de la deuda $192.869,81 \$$, por lo que no estaba cancelada al completo. Respecto al otro compromiso de la disposición de bases aérea y marítima para organizar una expedición contra Trujillo, ni siquiera se llegó a tratar al comprobarse el incumplimiento de la primera parte.

No obstante todo lo anterior, en diciembre de 1948, Figueres había considerado canceladas sus cuentas con la Legión y declaró que, en adelante, ya solo existiría el Ejército de Liberación Nicaragüense (ELN), a cuyo frente estaría el nicaragüense Rosendo Argüello -Comandante en Jefe del Ejército de Liberación Nicaragüense- que explicaba esa decisión de Figueres al general Miguel Ángel Ramírez:

Según notificación del señor presidente Figueres, él ya canceló cuentas con la exLegión Caribe y considera que esa organización ya no tiene razón de ser. En consecuencia, el único cuerpo organizado en adelante para la lucha contra Somoza sería el

\footnotetext{
62 Respuestas al cuestionario formulado por el periodista e historiador Guillermo Villegas Hoffmeister a Horacio Ornes. Santo Domingo, 10-6-1988. AHOC/CDM, Caja 10.

63 Se añadía una lista de las armas y municiones enviadas a Costa Rica, que esperaba le fueran restituidos, junto al acordado préstamo por una cantidad similar a aquella; otros 20.000 \$ gastados en la compra del avión -aunque no llegara, por un accidente donde murieron dos pilotos- que los podía Figueres devolver en dinero o con el envío de otro avión y el resto del material. Finalmente, reclamaba también un nuevo préstamo por la misma cantidad de 20.000\$ empleada o su valor en material de guerra. Carta del General Juan Rodríguez a Figueres de 26 de julio de 1948. Legión Caribe. AHOC/CDM, Caja 10.

64 Los delegados fueron: José Figueres, presidente, Fernando Valverde, ministro de Gobernación y Francisco Orlich, ministro de Fomento.
} 
Ejército de Liberación Nicaragüense (ELN), comandado por el suscrito y sólo esta organización continuaría recibiendo el apoyo de los gobiernos amigos. Los miembros de la ex-Legión que deseen luchar por la libertad de Nicaragua, deberán incorporarse al ELN para unificar así todas las fuerzas opositoras a las dictaduras ${ }^{65}$.

Así se lo comunicó Rosendo Argüello -satisfecho todavía de la mención que hacía Figueres de la continuidad en su ejército- al representante de los dominicanos, Miguel Ángel Ramírez. No hubo en la orden de transmisión del mensaje alusión alguna a los dominicanos o a Trujillo, ni en concreto a quien había sido el Jefe del "Comité Supremo Revolucionario" de la Legión, el general Juan Rodríguez.

Fue evidente que Figueres había cambiado de opinión, se autoexcluía de la Legión del Caribe e, incluso, la disolvía unilateralmente. Siendo ya presidente de la Junta Fundadora de la Segunda República, su comportamiento se debió, al menos, a tres razones: por una parte, sus planes como futuro jefe de Estado chocaban con los compromisos contraídos con la Legión del Caribe. El sector de costarricenses que le había apoyado -la oligarquía cafetalera seguidora de Ulate-, incluidos los miembros de la Junta, le presionó para que se desentendiera de dichas promesas y a Figueres lo que más le interesó, a partir de entonces, fueron los apoyos del interior del país. De hecho, días después de que Figueres disolviera la Legión, los legionarios que habían permanecido en Costa Rica de junio a diciembre de 1948, a la espera de próximas actividades, salieron del país. El lugar de próximas concentraciones de exiliados, en adelante, sería la Guatemala de Arévalo ${ }^{66}$.

En segundo lugar, la abolición del ejército en Costa Rica el 1 de diciembre de 1948, hacía difícil explicar a la Junta que se siguiera prestando ayuda militar a la Legión del Caribe. Junto a ello, en la Junta se habían desatado luchas de poder, divisiones y rivalidades, una de cuyas causas había sido la aceptación o no de "los combatientes venidos del extranjero" 67.

La eliminación del ejército se incorporaría después a la Constitución de 1949 y sería una de las medidas más valoradas del gobierno de la Junta presidido por Figueres porque permitió dedicar los presupuestos antes asignados al ejército, sobre todo, al incremento del de educación ${ }^{68}$. Pero llevó parejo el abandono de los compromisos con los legionarios porque el ambiente ya aconsejaba su expulsión del país. Incluso, el general dominicano M. A. Ramírez tuvo que aclarar al ministro de Seguridad Pública, Edgar Cardona, y a la propia Junta de Gobierno, que él y sus compañeros -residentes todavía en Costa Rica- no estaban en rebeldía, de lo que se les había em-

\footnotetext{
65 Carta de Rosendo Argüello al General M.A. Ramírez. 9-12-1948. Legión Caribe. AHOC/CDM, Caja

66 Desde entonces, se empezó a planificar la futura invasión de Luperón a la República Dominicana, organizando toda la operación desde Guatemala. Líneas generales del plan de invasión e insurrección del país. 31 de mayo de 1949. Revolución Costa Rica 1948. Legión Caribe. AHOC/CDM, Caja 10.

67 Solís, 2006, pp. 374-376.

68 Acerca del tema de la abolición del ejército, véase: GÁmEz, 2001, pp. 59-63. Asimismo, opiniones en prensa sobre el tema en: Chaverri Fonseca, Amalia. "Ni para jugar". La Nación, San José, C.R., 27 de noviembre de 2003; Cruz de Lemos, Vladimir de la. "Abolición del ejército". Al Día, San José, C.R., 9 de diciembre, 2003; Pastor, José Antonio. "Vivir sin ejército no es una utopía". Tiempos del Mundo, San José, C.R., 25 de diciembre, 2003; "El significado de la abolición del ejército". Tribuna Económica, 4(12):7-8, Diciembre de 1986.
} 10. 
pezado a acusar. Los exiliados de la Legión todavía confiaban en la ayuda de Figueres y quisieron dejar claro que no tenían ninguna actitud en contra ${ }^{69}$.

Por último, en diciembre de 1948, Somoza -que también había ayudado a Picado porque apoyaba a quien estuviera contra Figueres- respondió a otra petición de Calderón Guardia. Fue entonces cuando la OEA impuso un cese de hostilidades que Figueres aceptó tanto por presiones de EE.UU. como por conveniencia: un mes antes, todavía bajo la amenaza de la invasión calderonista-nicaragüense, el embajador norteamericano, Nathaniel P. Davis, había dicho a Figueres que, para que se aprobase un envío de armas a Costa Rica, tendría que tomar alguna medida que demostrara sus intenciones pacíficas. Fue entonces cuando anunció que los miembros de la Legión Caribe estaban próximos a desmovilizarse y que abandonarían el país. Poco después, el $1^{\circ}$ de diciembre se anunció también la abolición del ejército costarricense ${ }^{70}$.

Muy poco después fue cuando Figueres declaró su salida de la Legión del Caribe -siempre considerada "comunista" por EE.UU. y avalada por la URSS en la propaganda trujillista- y la disolución de la misma ${ }^{71}$.

El abandono de Figueres de la Legión del Caribe ha sido explicado por algunos autores como necesario para que continuara el proceso hacia una nueva Costa Rica. Así, dice C. E. Alemán:

Figueres no fue capaz de mantener su apoyo a la Legión del Caribe mientras avanzaba su proyecto para una nueva Costa Rica. Además, y más significativamente, ambos, la Junta y Figueres, se dieron cuenta de que para apoyar la afirmación de que su revolución era auténticamente costarricense tenían que librarse de los exiliados que los habían ayudado a alcanzar su victoria ${ }^{72}$.

Dicha interpretación es refrendada por M. Olander, al decir que la amenaza de los exiliados para la soberanía de Costa Rica "hizo políticamente conveniente minimizar su participación ${ }^{73}$ ". Sin embargo, la percepción de los coetáneos implicados, especialmente de los dominicanos, fue de absoluta sorpresa y frustración. En consecuencia, perdidas las esperanzas en la colaboración prometida, el primero de abril de 1949, el general M.A. Ramírez se dirigió a la Junta de Gobierno de Costa Rica para reclamarle las deudas monetarias, pero también las morales o de solidaridad, en una carta seguida de un dossier con amplísima documentación ${ }^{74}$. En síntesis, señalaba lo que presenta el cuadro:

69 Cartas del General M.A. Ramírez a Edgar Cardona y a la Honorable Junta de Gobierno de Costa Rica, de 9 y 11 de diciembre de 1948. Revolución Costa Rica 1948. Legión Caribe. AHOC/CDM, Caja 10.

70 ACUÑA, 1974, pp. 369-370; 1998, pp. 57-59.

71 Carta de Rosendo Argüello al General M.A. Ramírez. 9-12-1948. Legión Caribe. AHOC/CDM, Caja 10.

72 Alemán, 2013, p. 130.

73 Olander, 1996, pp. 249-250.

74 Se trata de 120 páginas con los datos pormenorizados de todo lo expuesto y reclamado en la carta: cantidades monetarias adeudadas y pagadas por Costa Rica a cuenta del general Rodríguez, nombres de oficiales, sueldos y gastos efectuados de toda clase. Es sorprendente el detallismo de las anotaciones que incluyen las fechas de libramiento de cada uno de los cheques con el número de los mismos en toda clase de pagos y contenido de las facturas. Dossier de Anexos a la Carta del General M.A. Ramírez, Comandante de la ex-Legión del Caribe a la Honorable Junta de Gobierno de Costa Rica, en representación del General Juan Rodríguez García, de 1 de abril de 1949. AHOC/CDM, Caja 11. 
Tabla 1. Estado de cuentas de la Junta de Costa Rica con el general Juan Rodríguez.

\begin{tabular}{|l|l|l|l|}
\hline Clase de conceptos & Deuda de C.R. & Clase de conceptos & Abonos hechos C.R. \\
\hline $\begin{array}{l}\text { Inv. en campaña } \\
\text { militar }\end{array}$ & $86.340,52 \$(44,76 \%)$ & Gastos de guerra ${ }^{75}$ & $125.000 \$(65,86 \%)^{76}$ \\
\hline $\begin{array}{l}\text { Desgaste y ayuda, } \\
\text { según Convenio de } \\
1947^{77}\end{array}$ & $106.520,29 \$(55,24 \%)$ & $\begin{array}{l}\text { Sueldos de oficiales, tro- } \\
\text { pa, avituall., y otros }\end{array}$ & $64.783 \$(34,14 \%)$ \\
\hline Total adeudado & $192.860,81 \$(100 \%)$ & $\begin{array}{l}\text { Total ya abonado por } \\
\text { Costa Rica }\end{array}$ & $189.783,28 \$(100 \%)$ \\
\hline
\end{tabular}

Fuente: Elaboración propia a partir de los datos de los Anexos 1 a 13 de las reclamaciones del general Juan Rodríguez a Costa Rica, de 1 de abril de 1949. Dossier de Anexos, AHOC/ CDM, Caja 11.

Puesto que el total ya pagado en uno u otro concepto por Costa Rica ascendía a $189.783,28$ \$, y el total que se adeudaba era de $192.860,81 \$$, el saldo faltante para cubrir el monto total de la reclamación dominicana ascendía a 3.077, 53 \$, dado que varios conceptos no se habían cobrado ${ }^{79}$. Esta cantidad, que actualmente no parece demasiado grande, significaba en 1948, por ejemplo, la sexta parte del precio de un avión de guerra ${ }^{80}$. Asimismo, serviría como referente el dato de que en la pormenorización de las cuentas de la propia Legión del Caribe, un grado de mayor o general del ejército recibía como salario unos 150 \$ al mes, un coronel, 120 \$ y un capitán, unos $89 \$ \$^{81}$. Es decir, que la deuda habría alcanzado para pagar su salario a uno de los más altos grados del ejército durante dos años ${ }^{82}$. Una cantidad apreciable para ser

75 Lo que se ha resumido en el concepto de "gastos de guerra" se refiere a armas y equipos bélicos, además de indemnizaciones según el Convenio suscrito por ambas partes. Anexo $n^{\circ} 4$, pp. 8-10 de la reclamación de 1 de abril de 1949. Dossier de Anexos. AHOC/CDM, Caja 11.

76 Cheque librado contra el National City Bank de Nueva York el 28-9-1948, p. 30 de la reclamación de 1 de abril de 1949. Dossier de Anexos. AHOC/CDM, Caja 11.

77 Por "Desgaste y ayuda según Convenio" se entiende: Indemnización para reponer el desgaste de material y como contribución para ayudar a la revolución dominicana, de acuerdo con el Convenio de diciembre de 1947. Anexo n 2, pp. 8-10. Dossier de Anexos. AHOC/CDM, Caja 11.

78 En "Sueldos de oficiales, avituallamiento y otros" se han incluido: sueldos de oficiales de todo tipo, tropa, gastos de la Casa Cuartel (alojamiento de oficiales de abril a septiembre de 1948), gastos de transporte, indemnización y desmovilización de la Legión del Caribe. Anexo nº 6, pp. 13-90. Dossier de Anexos. AHOC/ CDM, Caja 11.

79 No se cobró a Costa Rica ni un avión, comprado por el general por 20.000 \$, porque un accidente lo había derribado en Guatemala, ni un lote de armamento que el general cedió y dejó fuera de las cuentas reclamadas. Anexos no 2 y 4, pp. 4-6 y 8-10. Dossier de Anexos. AHOC/CDM, Caja 11.

80 El avión comprado por el general Juan Rodríguez costó 20.000 \$. Anexo $n^{\circ}$ dos, pág. 4 de la reclamación de 1 de abril de 1949. Dossier de Anexos. AHOC/CDM, Caja 11.

81 Los sueldos se pagaban en colones, pero se indica que el cambio en dicha fecha es 5,67 \$ por 1 colón. En los datos arriba expuestos está la conversión ya realizada. Sueldos de oficiales ex-combatientes de la Legión del Caribe, de junio a diciembre de 1948. Anexo nº 6, pp. 13-90 de la reclamación de 1 de abril de 1949. Dossier de Anexos. AHOC/CDM, Caja 11.

82 Trasladándolo a la actualidad, en que el salario de un general puede oscilar entre 2.500 y $5.000 \$$, en América Latina, la deuda hubiera ascendido, actualmente, a unos 90.000 \$. 
reclamada, sobre todo teniendo en cuenta que el general Rodríguez habría empleado su fortuna personal. Además, Horacio Ornes anotaría en sus escritos que no les había satisfecho que Figueres no devolviera armas, sino dinero en efectivo y, tan a la baja, que lo devuelto no representaba ni el 50\% de lo acordado en el Pacto. También, y muy importante, Figueres había dejado sin efecto la parte de reciprocidad que había firmado en 1947. No cumplió con el compromiso firmado que consistía en:

devolver al General Rodríguez una cantidad de elementos de guerra igual a la recibida y prestar de sus propios arsenales otra cantidad, por lo menos igual, a la prestada por aquel, que deberá restituirse tan pronto como sea destruido el régimen de Trujillo ${ }^{83}$.

Por añadidura, no fue la del general Rodríguez la única deuda que había dejado pendiente Costa Rica. También, dos meses antes, le había reclamado la devolución de otra cantidad otro miembro de la Legión, el coronel hondureño Jorge Rivas, relativa a una compra de armas -unos 30.000 colones (unos 5.291 \$ de la época) de los que existía constancia en el Estado Mayor- después del período bélico de marzo y abril. Jorge Rivas había comprado con su propio dinero esas armas a los costarricenses que se habían apropiado de las mismas al término de la contienda. De este modo evitaba al gobierno de Costa Rica el problema de tener armas dispersas por el país y las preservaba para utilizarlas más adelante contra la dictadura hondureña de Tiburcio Carias. Incluso, habían prestado las armas cuando Costa Rica las volvió a necesitar, posponiendo su propia revolución ${ }^{84}$. Figueres negó todos los hechos: mantuvo que había ordenado requisar las armas reclamadas para que no quedaran dispersas y negó la compra de las mismas; de ahí que afirmó no tener deuda alguna ${ }^{85}$. No hay más datos para decantarse por uno u otro oponente y saber quien tenía la verdad, pero Rivas aportaba el dato de que la anotación de esa deuda constaba en el Estado Mayor.

Los impagos de las deudas de guerra no debían ser algo inusual porque el mismo Jorge Rivas le había solicitado tiempo atrás también a Jacobo Arbenz -entonces ministro de Defensa de Guatemala del gobierno de José Arévalo-, y más tarde al propio Arévalo, otra deuda de armas de unos 3.000 \$ compradas por el propio Rivas cuando en diciembre de 1948 el gobierno revolucionario de Guatemala se había sentido amenazado ${ }^{86}$. Tampoco hay datos acerca de la cancelación o no de esta deuda. Sin embargo, aun con casos como los anteriores, que pudieron darse con alguna frecuencia, lo cierto es que los más afectados fueron los dominicanos.

83 Artículo II-c del Convenio de 16-12-1947. Convenio del Pacto del Caribe, firmado en La Habana, el 14 de noviembre y el 16 de diciembre de 1947. Legión Caribe. AHOC/CDM, Caja10.

84 Cartas desde La Habana del coronel Jorge Rivas a José Figueres de 12-10-1949, 10-1-1950 y 18-11950. Rivas escribe a Figueres con timidez, no queriendo molestar, pero con firmeza en su reclamación. Le expone que su situación económica era pésima y que su esposa estaba grave y lo necesitaba para atenderla. Le recuerda, además, que estuvieron juntos - Rivas y Figueres- a punto de morir y corrieron enormes peligros (en S. Cristóbal del Sur, en El Empalme y en El Tejar) por lo que no era una deuda cualquiera, sino que debía haber sido “digna de gratitud por parte de Costa Rica". Dossier de Anexos. AHOC/CDM, Caja 11.

85 Carta de José Figueres al coronel Jorge Rivas de 7-3-1950. Dossier de Anexos. AHOC/CDM, Caja 11.

86 Rivas afirmó que había comprado las armas con la autorización del embajador guatemalteco Francisco Valdés Calderón, trasladadas de Costa Rica a Guatemala y entregadas por él mismo al coronel Cozensa. Cartas del coronel Jorge Rivas al ministro de Defensa de Guatemala, Jacobo Arbenz de 28-12-1949 y al presidente José Arévalo el 3-10-1950. Dossier de Anexos. AHOC/CDM, Caja 11. 
Horacio Ornes declaró, muchos años después, que sus relaciones con Figueres se habían congelado desde diciembre de 1948, cuando aquel, unilateralmente, dio por disuelta la Legión del Caribe. En su opinión, había tenido un claro incumplimiento y los legionarios siempre consideraron que Figueres había hecho un magnífico negocio, pues la compensación económica quedó muy lejos del valor del equipo ${ }^{87}$. Pero también admitiría que, a finales de la década de 1950, había prestado a la causa dominicana valiosos servicios políticos:

Las gestiones de Figueres, actuando como enlace entre el presidente Betancourt, el gobernador de Puerto Rico, Muñoz Marín, y los liberales norteamericanos, ayudaron mucho al aislamiento internacional del régimen. Pero el general Rodríguez siempre consideró que Figueres lo había traicionado y nunca más mantuvo relaciones, ni directas ni indirectas, con él ${ }^{88}$.

Ciertamente, Figueres contrajo una deuda económica y moral con los dominicanos que no canceló, aunque, en la segunda mitad de la década de 1950, cuando ocupó la Presidencia, hizo lo posible por desprestigiar a Trujillo en cuanto tuvo ocasión en los foros internacionales ${ }^{89}$. Sin embargo, eso no fue suficiente para hacer siquiera tambalear un régimen tan fuertemente apuntalado y se debería a otro grupo de opositores, que nada tuvo que ver con Costa Rica, la acción que puso fin a la dictadura.

De no haberse integrado en la Legión del Caribe, José Figueres no hubiera podido contar ni con las armas necesarias, ni con los militares que precisaba para ganar la guerra civil. Dominicanos, hondureños y nicaragüenses le aportaron a Costa Rica las armas, oficiales y experiencia en combate que aquella no tenía. Asimismo, sin la fortuna del general Juan Rodríguez y la amistad personal de Horacio Ornes con Arévalo y Grau San Martín, en aquel momento, nada de lo que ocurrió hubiera sido posible. La próxima acción contra la dictadura de Trujillo, el desembarco de Luperón de junio de 1949, sería protagonizado y desarrollado ya casi exclusivamente por dominicanos, con el resultado de diez fallecidos y cinco supervivientes ${ }^{90}$.

Respecto a Nicaragua, es indudable que se implicó mucho más en el futuro, de una u otra forma, aunque por proximidad, sin reactivar la Legión del Caribe. El siguiente intento de la oposición, de trágico final, fue el más grave atentado fallido contra Somoza, de 4 de abril de 1954. Entre sus componentes, todos muertos o capturados,

\footnotetext{
87 Cartas a Cándido de la Torre. Correspondencia de Horacio Ornes, 1985-87. AHOC/CDM, Caja 5.

88 Respuestas al cuestionario formulado por el periodista e historiador Guillermo Villegas a Horacio Ornes. Santo Domingo, 10-6-1988. AHOC/CDM, Caja 10.

89 Figueres fue "presidente de facto" de 1948 a 1949 y, posteriormente, electo de 1953-1958 y de 19701974.

90 Ornes, jefe de las operaciones de Luperón, quiso que no se olvidara la heroicidad de los expedicionarios que sacrificaron sus vidas y dejó constancia de sus nombres: Federico Horacio Henríquez, Hugo Kundhart, Salvador Reyes Valdez y Manuel Calderón Salcedo; los nicaragüenses Alejandro Selva y Alberto Ramírez y el costarricense Alfonso Leiton. También murieron los tres tripulantes norteamericanos y sobrevivieron los dominicanos José Rolando Martínez Bonilla, Tulio Arvelo Delgado, Miguel A. Feliú Arzeno, Horacio Ornes y el nicaragüense José F. Córdoba Boniche. Escritos de Horacio Ornes. Resumen para la futura juventud acerca de lo que fue el trujillato. $\mathrm{AHOC} / \mathrm{CDM}, \mathrm{Caja}^{\circ} 8$.
} 
había varios que habían formado parte de la Legión del Caribe ${ }^{91}$. La intervención de Figueres en dicha acción ha sido objeto de polémica constante. Él siempre lo negó, pero hay autores que aseguran su implicación y de la de Prío Socarrás de Cuba, lo mismo que en otra invasión de exiliados, posterior, en 1959, la denominada de Olama y Mollejones, entre cuyos apoyos se incluía también a Venezuela ${ }^{92}$.

Más tarde, cuando la oposición a Somoza se consolidó, encabezada por el FSLN, siempre contó con la vecina Costa Rica como lugar de retaguardia de la lucha guerrillera. Pero desde 1974, cuando despegó la recta final de la dictadura, Figueres solo ocuparía la jefatura del Estado unos meses, seguido de Daniel Oduber y Rodrigo Carazo.

Así pues, en la década de 1940 faltaban años para que en la República Dominicana otro movimiento terminara con la dictadura de Trujillo y muchos más todavía para que se organizara la oposición que en Nicaragua pondría fin a la dinastía de los Somoza.

Sucesos como los que condujeron a la disolución de la Legión del Caribe, entre la deslealtad, la traición o el aprovechamiento de recursos colectivos para usos particulares, permiten explicar algunos factores de la permanencia de las dictaduras centroamericanas. Si al exilio, la dispersión, el miedo al largo brazo de los tiranos y los problemas de financiación se unieron actuaciones como la de Figueres en aquel momento, es fácil comprender los motivos por los cuales ni la oposición en el interior ni en el exilio pudieron derrocar antes a dictadores de la talla de Trujillo, uno de los más duros y longevos del siglo XX.

\section{REFERENCIAS BIBLIOGRÁFICAS}

Acuña V., Miguel

1974 El 48. San José. Librería, Imprenta y Litografía Lehmann, S. A.

1998 La Junta y los Mitos del 48. San José. Ediciones Sanabria, S. A.

ACUÑa Ortega, Víctor Hugo

1992 Conflicto y Reforma en Costa Rica: 1940-1949. San José. Editorial EUNED. Serie Nuestra Historia, ${ }^{\circ} 17$.

Aguilar Bulgarelli, Óscar

2004 Costa Rica y sus hechos políticos de 1948. Problemática de una década. San José. Editorial EUNED.

91 Fue el fallido atentado contra Somoza del 4 de abril de 1954 perpetrado por un grupo de ex-oficiales desafectos al régimen, acompañados por otros civiles y encabezados por Pablo Leal Rodríguez, uno de los posteriormente ejecutados. Los más conocidos del resto del grupo, también ejecutados fueron: Adolfo Báez Bone -teniente ex-Guardia Nacional-, Luis Felipe Báez Bone, civil, Manuel Agustín Alfaro -teniente ex-Guardia Nacional-, José María Tercero Lacayo -capitán ex-Guardia Nacional-, Luis Felipe Gabuardi Lacayo, también civil, y otros quince más. Junto a ellos fue capturado y sometido a Consejo de Guerra, junto a otros, el coronel hondureño Jorge Rivas Montes. BozA, 2007, pp. 202-203.

92 Torres Lazo, 2002, pp. 108-116; Mendieta Alfaro, 1992, p. 44. El embajador español en Washington sostuvo que era algo sabido que Figueres les había apoyado, pero que EE.UU. no tenía pruebas y por ello no se había pronunciado la OEA. Despacho del embajador de España en Washington, José María de Areilza, 8 de junio de 1959. Archivo Ministerio de Economía y Competitividad de España. AMAEC, R-5435-14. 
Alemán, Carlos

2013 "Nicas belicosos: nicaragüenses en la guerra civil de Costa Rica". Anuario de Estudios Centroamericanos. Universidad de Costa Rica, $n^{\circ} 39$, pp. 111-141.

AMERINGER, Charles D.

1974 The democratic left in exile; the antidictatorial struggle in the Caribbean, 19451959. Coral Gables, Fla. University of Miami Press.

1978 Don Pepe: a political biography of José Figueres of Costa Rica. Albuquerque. University of New Mexico Press.

1996 The Caribbean Legion. Patriots, Politicians, Soldiers of Fortune, 1946-1950. Pennsylvania. Pennsylvania State University Press.

ArgüELlo, Rosendo

1954 Quiénes y cómo nos traicionaron. México, S.E.

Arvelo, Tulio

1981 Cayo Confites y Luperón. Memorias de un expedicionario. Santo Domingo. UASD. Colección Historia y Sociedad, $n^{\circ} 51$.

BeLl, John Patrick

1981 Guerra Civil en Costa Rica. Los sucesos políticos de 1948. San José. EDUCA. Ed. Universitaria Centroamericana.

Boza, Francisco

2007 Memorias de un soldado. Managua. Ed. Pavsa.

Caballero, Manuel

1987 El discurso del desorden. Caracas. Alfadil Ediciones - Colección Tópicos.

CALDERÓn, Manuel

2002 “La huelga de brazos caídos y la guerra civil de 1948”. Diálogos. Revista Electrónica de Historia. San Pedro de Montes de Oca, Universidad de Costa Rica, vol. 3, nº 1. En http://www.redalyc.org/articulo.oa?id=43930101.

CASSÁ, Roberto

1984 Modos de producción, clases sociales y luchas políticas. República Dominicana. Siglo XX. Santo Domingo. Punto y Aparte, Editores.

1992 Capitalismo y dictadura. Santo Domingo. Editora Universitaria.

2000 Historia social y económica de la República Dominicana. Santo Domingo. Ed. Alfa y Omega.

2010 "Los preparativos de la expedición de Luperón” (Conferencia dictada en la Academia Dominicana de la Historia, 18 de junio de 2010). Boletín del Archivo General de la Nación. Santo Domingo, año LXXII, vol. XXXV, nº 127, pp. 69-97.

CERDAS CRUZ, Rodolfo

1998 La otra cara del 48. Guerra Fría y movimiento obrero en Costa Rica, 1945-1952. Costa Rica. Editorial Universidad Estatal a Distancia (EUNED).

CORDERO, Michel

2009 "Movimientos de oposición a Trujillo en la década 1930-39”. Clio. Santo Domingo, $n^{\circ} 178$, pp. 149-174.

Crassweller, Robert

1966 Trujillo: The Life and Times of a Caribbean Dictador. New York. Macmillan. 
DíAz Arias, David

2009 Social Crises and Struggling Memories: Populism, Popular Mobilization, Violence, and Memories of Civil War in Costa Rica, 1940-1948. Bloomington. Indiana University. Tesis Doctoral inédita.

FIALLO, Fabio

2004 Fin de rêve à Saint-Domingue. Aux premières loges de l'histoire dominicaine. París. Ed. L'Harmattan.

GALÍNDEZ, Jesús de

1956 La era de Trujillo. Un estudio casuístico de dictadura hispanoamericana. Santiago de Chile. Editorial del Pacífico.

1999 La era de Trujillo. Santo Domingo. Ed. Cole.

GamboA, Manuel

2013 "El anticomunismo en Costa Rica y su uso como herramienta política antes y después de la guerra civil de 1948". Anuario de Estudios Centroamericanos. Universidad de Costa Rica, n 39, pp. 143-165.

GÁmez Solano, Uladislao

2001 José Figueres Ferrer. El hombre y su destino. Semblanza. San José. Ed. EUNA.

JimÉnez G., Carlos María

1948 La Legión del Caribe (Gloria y hazañas). San José. Ed. Borrasé.

LeHOUCQ, Fabrice

1992 "Conflicto de Clases, Crisis Política y Destrucción de las Prácticas Democráticas". Revista de Historia. San José de Costa Rica, no 25 (enero-junio), pp. 65-96.

1997 Lucha electoral y sistema político en Costa Rica, 1948-1998. San José. Ed. Porvenir.

LILón, Domingo

1999 "Propaganda y política migratoria dominicana durante la Era de Trujillo (19301961)". Historia y Comunicación Social. Santo Domingo, nº 4, pp. 47-71.

Mateo, Andrés

2004 Mito y cultura en la era de Trujillo. Santo Domingo. Ed. Manatí.

Mendieta Alfaro, Roger

1992 Olama y Mollejones. Managua. Impresiones Carqui.

Molina, Iván - LeHoucQ, Fabrice

1999 Urnas de lo inesperado. Fraude electoral y lucha política en Costa Rica (19011948). San José. Ed. Universidad de Costa Rica.

OLANDER, Marcia

1996 “Costa Rica in 1948: Cold War or Local War?”. Americas. San José, n 52, pp. 465493.

ORNES, Germán

1958 Trujillo, Little Caesar of the Caribbean. New York. Thomas Nelson \& Sons.

ORNES, Horacio

1956 El desembarco de Luperón: episodio de la lucha por la democracia en la República Dominicana. México. Ediciones Humanismo.

Padilla Rus, Rigoberto

2002 Memorias de un comunista. Tegucigalpa. Ed. Guaymuras. 
RoJAs, Manuel

1986 Lucha Social y Guerra Civil en Costa Rica. 1940-1948. San José. Editorial Alma Mater.

RoDRÍGUEZ, Eugenio

1980 De Calderón a Figueres. San José. Editorial Universidad Estatal a Distancia (EUNED).

ROMERo PÉrez, Jorge Enrique

1998 "Reflexiones sobre algunos aspectos de la guerra civil de 1948". ABRA. San José, vol. 19, no 27-28, pp. 40-47.

SÁEnz CARbonell, Jorge

2004 “La Política Exterior”. En Rodríguez Vega (ed.), Costa Rica en el siglo XX (vol. III). San José. Ed. Eugenio Rodríguez Vega, pp. 220-264.

2013 "La Política exterior de la Junta Fundadora de la Segunda República". En SANZ CARBonell, Historia Diplomática de Costa Rica, 1949-1970. San José de Costa Rica. Universidad Nacional, pp. 1-37.

SILFA, Nicolás

1980 Guerra, traición y exilio: Una relación de hechos para la historia contemporánea de la República Dominicana. Barcelona. Edición del autor.

SoLís, Manuel

2006 La institucionalidad ajena: los años cuarenta y el fin de siglo. San José. Ed. Universidad de Costa Rica.

2007-2008 “El 48 como desborde trágico". Anuario de Estudios Centroamericanos. San José de Costa Rica, n 33-34, pp. 261-295.

TORRES, Edelberto

2007 La piel de Centroamérica. Costa Rica. FLACSO.

Torres Lazo, Agustín

2002 La saga de los Somoza. Managua. Hispamer.

VÁzQUEz GARCíA, Humberto

2012 La Expedición de Cayo Confites. La Habana. Ed. Oriente.

VEGA, Bernardo

1986 Unos desafectos y otros en desgracia: Sufrimientos bajo la dictadura de Trujillo. Santo Domingo. Fundación Cultural Dominicana.

Villegas HofFMeISTER, Guillermo

1998 La guerra de Figueres: crónica de ocho años. San José. Editorial Universidad Estatal a Distancia (EUNED).

WIARDA, Howard

1970 Dictatorship and development. The Methods of Control in Trujillo's Santo Domingo. Gainesville. University of Florida Press. 